\title{
Engaging Social Science Students with Statistics: Opportunities, Challenges and Barriers
}

Charlotte Brookfield

Cardiff University, brookfieldc@cardiff.ac.uk

Malcolm Williams

Cardiff University, williamsmd4@cardiff.ac.uk

Luke Sloan

Cardiff University, sloansl@cardiff.ac.uk

Emily Maule

emilymaule@live.co.uk

Follow this and additional works at: https://digitalcommons.usf.edu/numeracy

Part of the Social Statistics Commons, and the Sociology Commons

\section{Recommended Citation}

Brookfield, Charlotte, Malcolm Williams, Luke Sloan, and Emily Maule. "Engaging Social Science Students with Statistics: Opportunities, Challenges and Barriers." Numeracy 14, Iss. 2 (2021): Article 6. DOI: https://doi.org/10.5038/1936-4660.14.2.1386 


\title{
Engaging Social Science Students with Statistics: Opportunities, Challenges and Barriers
}

\begin{abstract}
In 2012, in a bid to improve the quantitative methods training of social science students in the UK, the $£ 19.5$ million Q-Step project was launched. This investment demonstrated a significant commitment to changing how we train social science students in quantitative research methods in the UK. The project has involved eighteen higher education institutions exploring and trialling potential ways of engaging social science students with quantitative approaches.

This paper reflects on the activities of one Q-Step centre based in the School of Social Sciences at Cardiff University. As well as describing some of the pedagogic changes that have been implemented, the paper draws on data to begin to evaluate the success of new approaches. Specifically, data showing the proportion of students undertaking a quantitative final-year dissertation project is used to measure the impact of these activities. The data presented in this paper suggest that resistance to learning quantitative research methods and engaging with such techniques has decreased. The data also indicates that students see this learning as beneficial for their own employability. Despite this, closer analysis reveals that several students change their mind about employing quantitative methods in their own research part way through their dissertation journey. We argue that while social science students are comfortable learning about quantitative approaches, they are less confident at applying these techniques. Thus, the paper argues that there is a wider challenge of demonstrating the relevance and appropriateness of such approaches to understanding the social world.
\end{abstract}

\section{Keywords}

dissertations, pedagogy, Q-Step, quantitative, research methods

\section{Creative Commons License}

\section{(c) (i) (9)}

This work is licensed under a Creative Commons Attribution-Noncommercial 4.0 License

\section{Cover Page Footnote}

Charlotte Brookfield is Senior Lecturer at Cardiff University's School of Social Sciences.

Malcolm Williams is Professor at Cardiff University's School of Social Sciences.

Luke Sloan is Professor at Cardiff University's School of Social Sciences.

Emily Maule is a graduate from Cardiff University's School of Social Sciences, who completed the BSc Social Analytics degree programme. 


\section{Introduction}

The crisis of number in UK social science was the subject of many research projects through the 2000s, eventually leading to the $£ 19.5$ million Q-Step initiative, launched in 18 universities (https://www.nuffieldfoundation.org/q-step). This project aimed to make a "step change" in the teaching of quantitative methods, through exploring and trialling potential ways of engaging social science students with quantitative approaches. The aim is to develop pedagogic tools or activities that will upskill social science students and allow them to critically consume and utilise number and later fill graduate positions where they can simultaneously analyse and interpret quantitative data and provide relevant and insightful commentary. Q-Step Centres have adopted a range of different approaches to dealing with this challenge. Early indications are that the Q-Step Centres have succeeded in increasing the number of students learning statistics and quantitative methods, and although this is to be welcomed, important questions remain about the sustainability of statistical education in the social sciences and whether such teaching can be broadened and deepened.

While this paper describes the challenge of teaching statistics to social science students in general, in discussing the data, there is a particular focus on the situation in sociology. ${ }^{1}$ The reason for this focus is twofold. Firstly, much more academic discussion, including the authors' own previous research, has explored the teaching and learning of statistics in British sociology. Secondly, and relatedly, it is within sociology that the place of quantitative methods has been most contested, and divides within the discipline seem most entrenched (Williams et al. 2017). Indeed, this is not a new perspective. In the 1970s, Tony Coxon described research methods as one of the most contested and reviewed part of sociology's curriculum and concluded that he had little "hope to have a stable curriculum in this area, at least in the foreseeable future" (Coxon 1973, 48). Because sociology is possibly the social science discipline that has shown the most "resistance" to the use of quantitative methods (Williams et al. 2017), it is within this discipline that we further discuss and consider the challenges to the teaching and learning of quantitative methods and statistics.

In this paper, we will reflect on specific pedagogic initiatives in one Q-Step Centre (Cardiff University's School of Social Sciences). As well as describing some of the pedagogic changes that have been implemented by the Centre, the paper draws on data to begin to evaluate the success of these new approaches in the context of more recent UK wide research. We outline and evaluate efforts taken at the Cardiff Q-Step Centre to make the teaching and learning of quantitative

\footnotetext{
${ }^{1}$ In this paper, we use the term quantitative methods to incorporate elements of design, sampling, and analysis, in which an understanding of statistics is a crucial element at every stage.
} 
research methods and statistics more commonplace and routine in the social sciences. Our endeavour is primarily operationalised in one specific question: has Q-Step activity increased the proportion of students in the social sciences using quantitative methods in their final year dissertations?

Dissertation proposal data shows that since the inception of the Q-Step Centre at Cardiff University's School of Social Sciences, there has been a steady increase in the percentage of students opting to use quantitative methods in their own research. However, our data indicates that some students opt out of undertaking a quantitative research project part way through their dissertation journey. This leads to questions over the factors which may contribute toward students' methodological decision making in their own research projects.

The data presented in this paper suggest that resistance to learning quantitative research methods and engaging with such techniques has decreased since 2015 and that in fact, many students see this learning as beneficial for their own employability. However, it is argued that deep divides, especially in British sociology and its analogous disciplines may result in students not appreciating the value or place of such approaches in their own discipline. In this paper, we will consider both the challenges and opportunities that emerge from the existing research and evolving pedagogy.

\section{The Place of Quantitative Methods in UK Social Sciences}

Several researchers have attempted to enumerate the level of quantification in UK sociology and its allied disciplines. For instance, Payne et al. (2004) reported that just $10.8 \%$ of the 102 papers presented at the British Sociological Association's Annual Conference in 2000 drew on quantitative analysis, compared to almost half of the papers found to utilise qualitative methods (the remaining papers were either non-empirical (35.5\%) or mixed methods (6.9\%)). Taking a longer view, MacInnes et al. (forthcoming) explored the output of Sociology, Sociological Review, and the British Journal of Sociology between 1960 and 2010. These authors found that over the 50-year period studied, the proportion of quantitative papers decreased from $32 \%$ to $16 \%$, while the proportion of purely qualitative papers rose from $8 \%$ to $43 \%$. Equally, an online survey of 1,024 sociologists working in UK higher education institutions in 2015/16 found that $9.0 \%$ of respondents classified themselves as quantitative researchers, in comparison, $57.7 \%$ who classified themselves as qualitative researchers (Brookfield 2017). The remaining survey participants classified themselves as either non-empirical researchers or mixed methods researchers.

Although most research in this area has focused on sociology, a similar issue has been reported in other UK social science disciplines. For instance, 
McCambridge et al. (2007) reviewed the output of 262 articles published in the British Journal of Social Work between 2000 and 2004 and found that over 65\% of articles published could be classified as qualitative research, compared to approximately one quarter of articles which presented quantitative research (the rest were either mixed methods or non-empirical). Of those articles classified as quantitative, a third contained descriptive statistics only and it was noted that research studies conducted outside of the UK were more likely to utilise more sophisticated statistical methods than UK-only projects. Likewise, in their comparative analysis of criminology in the UK and America, Cohn and Farrington (1990) found that approximately $40 \%$ of articles published in the British Journal of Criminology between 1984-1988 contained no quantification. Twenty percent of articles published made use of descriptive statistics only, $31.8 \%$ presented bivariate analysis, while less than $10 \%$ employed multivariate analysis. In comparison, approximately $30 \%$ of papers published in the same period in Criminology had no quantification. Just over $15 \%$ of articles utilised descriptive statistics only, a quarter presented bivariate analysis, while almost $30 \%$ utilised multivariate analysis.

What became known as "the problem of number" caused concern among commentators both in regard to the status, purpose, and future of the social sciences in the UK and in regard to issues relating to the transferable skills and employment prospects of graduates. Specifically, commentators have suggested that a lack of engagement with quantitative methods could potentially exclude British social sciences from social science research in other countries across the globe (Payne et al. 2004; Lynch et al. 2007). It has been argued that British sociology, in particular, lacks a coherent core compared with other national sociologies (HaPS 2010), and critics have maintained that no distinctive methodologies or methods can be associated with the discipline in the UK. This has fuelled concerns that UK social science students may not see the relevance of quantitative approaches to studying the social world (MacInnes 2009; MacInnes et al. 2016). Indeed, comparative studies have demonstrated that social science students in other countries receive much more training in quantitative methods compared to their peers in the UK. For instance, a content analysis of the availability and range of methods training in undergraduate degree programmes by Parker et al. (2008) highlighted that across all social science disciplines investigated (business, economics, geography, political science, psychology, and sociology), higher education institutions in Sweden and the Netherlands on average, required students to complete a greater number of research methods and quantitative methods modules. More recently, MacInnes et al. (2016) reported that in other countries, undergraduate students learnt about a greater range of statistical tests, especially multivariate analysis, and noted greater prevalence of statistics embedded in substantive teaching. This finding has exacerbated concerns about UK social science students' potential to fulfil graduate roles and even to critically consume media stories (Payne et al. 
2004). This concern about the quantitative abilities of UK social science students compared to their international peers is not new. In the early 1980s, comparing UK and USA sociology graduates, Frank Bechhofer commented that "there is little doubt that the average North American sociologists or graduate student can read the material in British journals whereas the majority of American journal writing is closed book to many British academics and most graduate students" (Bechhofer 1981, 501).

However, reports noting the difficulties of engaging social science students with quantitative methods are not exclusive to the UK. For instance, in Finland, the education and sociology students in Murtonen and Lehtinen's (2003) study reported a range of barriers to learning quantitative research methods, including rushed teaching, lack of prior knowledge, and confusion over when and why to use particular statistical tests. The discussion of how to effectively deliver quantitative research methods is becoming internationalised (Roberts 2012) with a push for greater sharing of both positive and negative experiences of teaching and delivering quantitative methods training to enable best practice across the globe. This paper aims to contribute toward this discussion by exploring UK students' level of engagement with quantitative research methods in their final year dissertations and suggesting possible barriers toward non-engagement with such approaches.

\section{Teaching and Learning Quantitative Methods in UK Social Science Degree Programmes}

Calls for more quantitative research training in UK social sciences degree programmes are not new. In the late 1980s, the Economic Social Research Council (ESRC) introduced formal postgraduate training guidelines which included a focus on developing the quantitative methods skills of postgraduate students. Through the 1990s and 2000s, the emphasis on quantitative methods learning was further developed (ESRC 2005). However, despite these further reforms, it was later decided that initiatives targeted exclusively at postgraduate students were of limited success. These students often arrived at postgraduate level courses with fixed ideas about quantitative methods and their relevance, a result of their undergraduate experiences and training. Indeed, in their study on the quantitative methods training provision of sociology undergraduates in the early 2000s, Rice et al. (2001) found that almost half of the higher education institutions studied $(n=82)$, reported that the teaching of quantitative methods, in sociology undergraduate programmes, contributed just $5-10 \%$ of the total teaching. This research also indicated that quantitative research methods teachers had concerns that quantitative methods teaching was isolated in the curriculum and that consequently students did not see the relevance or application of statistics in their substantive modules. 
In response to this dearth in training, in 2004, the ESRC established the National Centre for Research Methods (NCRM). Later, in 2006, the ESRC, British Academy, and HEFCE funded curriculum innovation and researcher development initiatives to investigate innovative quantitative methods teaching and to review best practice internationally (MacInnes 2009; Nuffield Foundation 2014). These projects have resulted in several academic publications as well as teaching resources that have been publicised and made accessible to all. For example, Carey et al. (2009) describe how they introduced new examples and assessment into the year 2 social research curriculum for politics students at Sheffield University in the hope of further engaging these students with quantitative methods. Likewise, at both Manchester University and Southampton University, activities were implemented to help encourage students to utilise quantitative approaches in their final year dissertations (Dale and Higgins 2008; Falkingham et al. 2009). For instance, at Manchester, workshops and student clinics were introduced (Dale and Higgins 2008), while in Southampton new summer/winter schools were rolled out (Falkingham et al. 2009).

However, these previous efforts have had limited success, often proving unsustainable because of a reliance on external pots of funding or involving major time and resource commitments from one or two key members of staff (MacInnes 2009; Bullock et al. 2014; Brookfield 2016). Equally, some of these projects have focussed exclusively on higher achieving students and therefore, while they provide some insight into how we can effectively train social science students in quantitative methods, the success of these initiatives across a whole cohort of students may be more varied or unpredictable. Subsequently, the Q-Step programme was launched, with the specific aim of leading on the improvement of quantitative methods teaching of social science students throughout their educational training career (Allebon 2013; Nuffield Foundation 2014; Grundy 2020). It is hoped that such a large-scale investment, across a number of higher education institutions, would enable considerable progress to be made on how best to teach quantitative methods.

This paper evaluates the activities of Cardiff University's Q-Step Centre. Specifically, the paper aims to somewhat track the quantitative learning journey of social science students, focussing on their transition from second year compulsory research methods training to their final year dissertation project. This makes for an interesting focus, as it is at this point that students transition from teacher led, prescribed activities and undertaking tasks with clean, accessible data, to a more independent engagement with quantitative research methods. It is important to take stock of the impact that the Q-Step Centre may be having on the proportion of students opting to undertake an independent quantitative research project in their final year. However, it is also important for the Centre to keep track of these students and identify potential barriers to them completing this work successfully. 


\section{Cardiff University's Q-Step Centre}

Cardiff University's School of Social Sciences is interdisciplinary and includes education, criminology, social policy, and social psychology as well as sociology. However, in its undergraduate programme, it is primarily a "sociology led" department, with academic staff supervising final year dissertations across subjects. Also, research methods teaching is standardised across disciplines. ${ }^{2}$

Prior to the establishment of the Q-Step Centre, the School of Social Sciences had begun to develop its quantitative methods teaching capacity and had participated in two ESRC pedagogic initiatives: the Curriculum Innovation project and the Researcher Development Initiative. These initiatives and previous quantitative methods teaching led the School to adopt a "core-periphery model" in its Q-Step Centre, aiming to develop a critical mass of quantitatively trained social scientists. The core of the model is the BSc Social Analytics degree programme. This programme has been functioning since 2015 and three cohorts have now graduated from the degree. Table 1 shows the number of students who have studied the degree programme since 2015 . Note, this table is organised by the year that students graduated/will graduate from the degree programme because in three of the cohorts listed, students have changed to the BSc Social Analytics degree programme in their second year of study.

Table 1

Number of Students Studying BSc Social Analytics

\begin{tabular}{cc}
\hline \hline Year graduating & $\begin{array}{c}\text { Number of students enrolled } \\
\text { on BSc Social Analytics }\end{array}$ \\
\hline $2017 / 2018$ & 5 \\
$2018 / 2019$ & 5 \\
$2019 / 2020$ & 2 \\
$2020 / 2021$ & 7 \\
$2021 / 2022$ & 2 \\
\hline \hline
\end{tabular}

The periphery of the Cardiff QStep model has been developed through the adoption of modules from the Social Analytics degree programme into other programmes within the School. For instance, Table 2 shows the number of students enrolled on modules which are compulsory for the Social Analytics degree programme. These numbers are significantly greater than the number of students enrolled on the degree programme each year. This finding demonstrates the breadth of students benefitting from the Q-Step funding and initiative in the School. For instance, while there were just 5 students who graduated from the degree programme in 2017/2018, 71 students in the School enrolled on the Lies, Damned Lies and Statistics module in their first year. It is worth noting that a wide-ranging curriculum review altered module diets and student choice for those graduating in the academic year 2019/2020 onward; this structural change can explain the slight drop in numbers studying modules from the BSc Social Analytics degree programme for these cohorts. "Embedding" of quantitative methods in substantive

${ }^{2}$ Students taking BSc Q-Step, the "core" Q-Step programme have a greatly enhanced quantitative methods curriculum. Students from other subjects may take these modules as options. 
modules has also been adopted in the School of Social Sciences, thus increasing the reach of the initiative across degree programmes in the social sciences (Williams et al. 2015). This practice has involved embedding examples of quantification in substantive modules as well as drawing on examples of quantitative research across the social sciences when delivering research methods training.

Table 2

Number of Students Enrolled on Modules from the BSc Q-Step Degree Programme

\begin{tabular}{|c|c|c|c|c|c|c|}
\hline $\begin{array}{c}\text { Year } \\
\text { Graduating }\end{array}$ & $\begin{array}{c}\text { Lies, } \\
\text { Damned } \\
\text { Lies and } \\
\text { Statistics } \\
\text { (Year 1 } \\
\text { Module) }\end{array}$ & $\begin{array}{c}\text { Philosophy and } \\
\text { Methodology } \\
\text { (Year } 1 \\
\text { Module) }\end{array}$ & $\begin{array}{l}\text { Real World } \\
\text { Research } \\
\text { with } \\
\text { Placement } \\
\text { (Year 2 } \\
\text { Module) }\end{array}$ & $\begin{array}{l}\text { Knowing the } \\
\text { Social } \\
\text { World: } \\
\text { Online and } \\
\text { Offline (Year } \\
2 \text { Module) }\end{array}$ & $\begin{array}{l}\text { Analysing } \\
\text { Social } \\
\text { Change } \\
\text { (Year 3 } \\
\text { Module) }\end{array}$ & $\begin{array}{c}\text { Experiments } \\
\text { in Knowing } \\
\text { (Year } 3 \\
\text { Module) }\end{array}$ \\
\hline $2017 / 2018$ & 71 & 41 & 13 & 19 & 11 & 12 \\
\hline $2018 / 2019$ & 53 & 57 & 12 & 20 & 20 & 12 \\
\hline $2019 / 2020$ & 26 & 35 & 7 & 40 & 23 & 8 \\
\hline $2020 / 2021$ & 29 & 19 & 14 & 42 & $\mathrm{n} / \mathrm{a}$ & $\mathrm{n} / \mathrm{a}$ \\
\hline $2021 / 2022$ & 46 & 25 & $\mathrm{n} / \mathrm{a}$ & $\mathrm{n} / \mathrm{a}$ & $\mathrm{n} / \mathrm{a}$ & $\mathrm{n} / \mathrm{a}$ \\
\hline
\end{tabular}

\section{Method}

This paper draws on taught module and dissertation data in order to evaluate the effectiveness of Cardiff University's Q-Step Centre. At this stage much of the data is indicative, rather than conclusive, but possibly if considered alongside data from other Q-Step centres, may indicate directions in the "step change" that was the aim of the programme (Grundy 2020).

Module evaluation data is used to determine social science students' level of satisfaction with learning quantitative research methods. These data are taken from a year 2 compulsory social research methods module. For some students in the School of Social Sciences (depending upon their degree programme and module choices), this is the last opportunity for them to receive any quantitative methods and statistics training before commencing their final-year dissertation project. The module provides students with the opportunity to analyse teaching datasets downloaded from the UK Data Service using SPSS. Students become familiar with univariate and bivariate analysis and are introduced to multivariate analysis. The data presented in this paper comes from the 2019/2020 cohort of $2^{\text {nd }}$ year students and contains 157 responses.

During their second year of study, students are asked to indicate whether or not they would like to complete a dissertation in their final year. Students register their interest by completing a short online survey which includes a brief description of the project that they would like to undertake as well as an indication of the methodological approach they intend to use. This paper looks at dissertation proposal data from the academic years 2017/2018, 2018/2019, and 2019/2020. The dissertation proposal data for 2017/2018 includes 167 cases. The 2018/2019 data includes 161 cases. Meanwhile, the dissertation proposal for 2019/20 includes 144 
cases. The students in the 2020 dataset are also the students who completed the 2019/2020 module evaluation for year 2 social research methods.

As part of the dissertation module in their final year of study, students are required to present their work in a School level conference. Prior to the conference, each student writes an abstract (approximately 250 words). This paper presents a content analysis of these abstracts. This approach mirrors that taken by previous researchers exploring the place of quantification in the mainstream journals and national conferences (for instance, Payne et al. 2004; MacInnes et al. forthcoming). The abstracts were coded to signify whether the students' project used a quantitative, qualitative, or mixed methods approach. Only a very small number of dissertations each year are theoretical or non-empirical and therefore are excluded from the analysis. Other information that was coded included the degree programme of the student and the subject area of the dissertation. This coding was completed for dissertation conference abstracts for the following academic years: 2015/2016, 2016/2017, 2017/2018, 2018/2019, and 2019/2020. For 2015/2016, 121 abstracts were coded, 124 abstracts were coded for 2016/2017, 129 abstracts were coded for 2017/2018, 167 abstracts were coded for 2018/2019, and finally, 130 abstracts were coded for 2019/2020.

Table 3 explains the datasets available for each cohort of students. The academic year in the table refers to the period in which the cohort of students for whom the data relates to were/will be in their final year of study, completing the dissertation module, and graduating from their degree programme. Note the difference between the number of students who initially registered for the dissertation module and the number of students' abstracts coded can be explained by the fact that students have a "cooling off" period at the start of each academic year to decide whether or not they want to complete a module. This can result in students changing modules in the early stages of the semester. In addition, the small number of theoretical, non-empirical abstracts have been excluded from the analysis, as have those abstracts which did not mention a method.

Table 3

Available Data for Each Academic Year

\begin{tabular}{llllll}
\hline \hline 2015/2016 & 2016/2017 & 2017/2018 & 2018/2019 & 2019/2020 & 2020/2021 \\
\hline & & & & Module \\
Evaluation Data & & \\
& & & & \\
& & $\begin{array}{l}\text { Dissertation } \\
\text { Proposal Data }\end{array}$ & $\begin{array}{l}\text { Dissertation } \\
\text { Proposal Data }\end{array}$ & $\begin{array}{l}\text { Dissertation } \\
\text { Proposal Data }\end{array}$ \\
Dissertation & Dissertation & Dissertation & Dissertation & Dissertation & \\
Conference & Conference & Conference & Conference & \\
Registration & Registration & Registration & Registration & Registration \\
Data & Data & Data & Data & Data & \\
\hline \hline
\end{tabular}

Looking at all these datasets together allows us to somewhat track the quantitative learning experience of students and identify possible barriers to engaging students with such approaches. 


\section{Findings}

\section{Year-2 Social Research Methods Module Evaluation Data}

All students in the School of Social Sciences, regardless of degree programme, must take compulsory research methods modules in both years one and two. In addition, under the "core and periphery model" adopted by the Cardiff Q-Step Centre, students from across the School can opt to study additional quantitative methods modules. These modules have proven popular with students. Anecdotal evidence suggested that the quantitative content of these new modules was well received and was evidenced by increasing numbers of students opting to take further quantitative methods modules (see Table 2). Up until last year we had only inconclusive and anecdotal evidence about effectiveness, however, in December 2019 a short online module evaluation survey was sent to all second-year students during their last seminar for the quantitative part of their compulsory social research methods module. One hundred fifty-seven students completed the survey.

Table 4

Module Evaluation Data for 2020/21 Cohort: Learning on the Module

\begin{tabular}{lcc}
\hline \hline & $\begin{array}{c}\text { "I have learnt a lot in } \\
\text { the quantitative } \\
\text { methods training on } \\
\text { this module." } \\
(\boldsymbol{\%})\end{array}$ & $\begin{array}{c}\text { "The quantitative } \\
\text { skills that I have learnt } \\
\text { will help with my } \\
\text { future employability." } \\
(\%)\end{array}$ \\
\hline Strongly Agree & 39.5 & 26.1 \\
Agree & 44.6 & 40.8 \\
Neither Agree nor Disagree & 8.9 & 22.3 \\
Disagree & 4.5 & 8.3 \\
Strongly Disagree & 2.5 & 2.5 \\
\hline Total & 157 & 157 \\
\hline \hline
\end{tabular}

Students were asked to indicate their level of agreement with the following statement: "I feel I have learnt a lot on the quantitative part of this module" (see Table 4). In total, $85 \%$ of the students

strongly agreed or agreed with this statement. Equally, $66 \%$ of students strongly agreed or agreed with the statement "the quantitative skills that I have learnt on this module will help my future employability."

Table 5

Module Evaluation Data for 2020/21 Cohort: Ratings of Lectures and Seminars

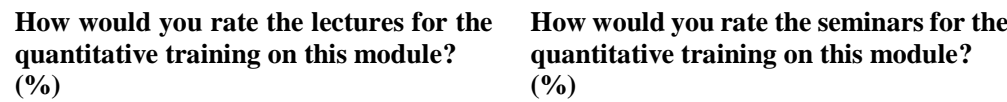

How would you rate the seminars for the quantitative training on this module? (\%)

\begin{tabular}{lcc}
\hline $\mathbf{1 = P o o r}$ & 4.6 & 1.9 \\
$\mathbf{2}$ & 10.3 & 1.9 \\
$\mathbf{3}$ & 19.4 & 10.3 \\
$\mathbf{4}$ & 31.0 & 32.7 \\
$\mathbf{5 = E x c e l l e n t}$ & 34.8 & 53.2 \\
\hline Total & 155 & 156 \\
\hline \hline
\end{tabular}


Thirty-five percent of students rated the lectures for the quantitative training on the module as excellent, and over half of students rated the seminars for the quantitative training on the module as excellent. Fewer than $5 \%$ of students rated either the lectures or seminars for the quantitative training on the module as poor (see Table 5). As shown in Table 6, 58\% of the students who were planning to undertake a final year dissertation project indicated that they were planning to do a quantitative research project next year.

Table 6

Module Evaluation Data for 2020/21 Cohort: Plan to Use Quantitative Methods in Dissertation

\begin{tabular}{lc}
\hline \hline & "I will use quantitative methods \\
in my dissertation next year." $(\boldsymbol{\%})$
\end{tabular}

\section{Final-Year Dissertation Proposal Data}

For the academic year 2018/2019, 167 students registered for the final year dissertation module. Almost $60 \%$ of the students $(58 \%)$ indicated that they were planning to undertake a qualitative dissertation research project (see Table 7). Meanwhile, a third of students suggested that they were planning to undertake quantitative research for their dissertation project. The remaining $7.7 \%$ of students were hoping to do a mixed methods project.

Table 7

Dissertation Proposal Data

\begin{tabular}{lccc}
\hline \hline & $\mathbf{2 0 1 8 / 2 0 1 9}$ & $\mathbf{2 0 1 9 / 2 0 2 0}$ & $\mathbf{2 0 2 0 / 2 0 2 1}$ \\
& $(\boldsymbol{\%})$ & $(\mathbf{\%})$ & $(\mathbf{\%})$ \\
\hline Qualitative & 58.7 & 56.5 & 61.8 \\
Quantitative & 33.5 & 30.4 & 29.9 \\
Mixed Methods & 7.7 & 13.0 & 8.3 \\
\hline Total & 167 & 161 & 140 \\
\hline \hline
\end{tabular}

For the academic year 2019/2020, 161 students registered to do a final year dissertation project. Over half of the students $(56 \%)$ were planning to undertake qualitative research for their dissertation project. Meanwhile, 30\% indicated that they were planning to use quantitative approaches in their dissertation. The remaining $13 \%$ planned to do a mixed methods project.

For the academic year 2020/2021, 144 students registered to do a final year dissertation project. Sixty-two percent of students indicated that were planning to do a qualitative dissertation, while $30 \%$ were planning to do a quantitative dissertation project. The remaining $8.3 \%$ of students indicated that they were planning to do a mixed methods dissertation research project. These data are summarised in Table 4 and Figure 1. 


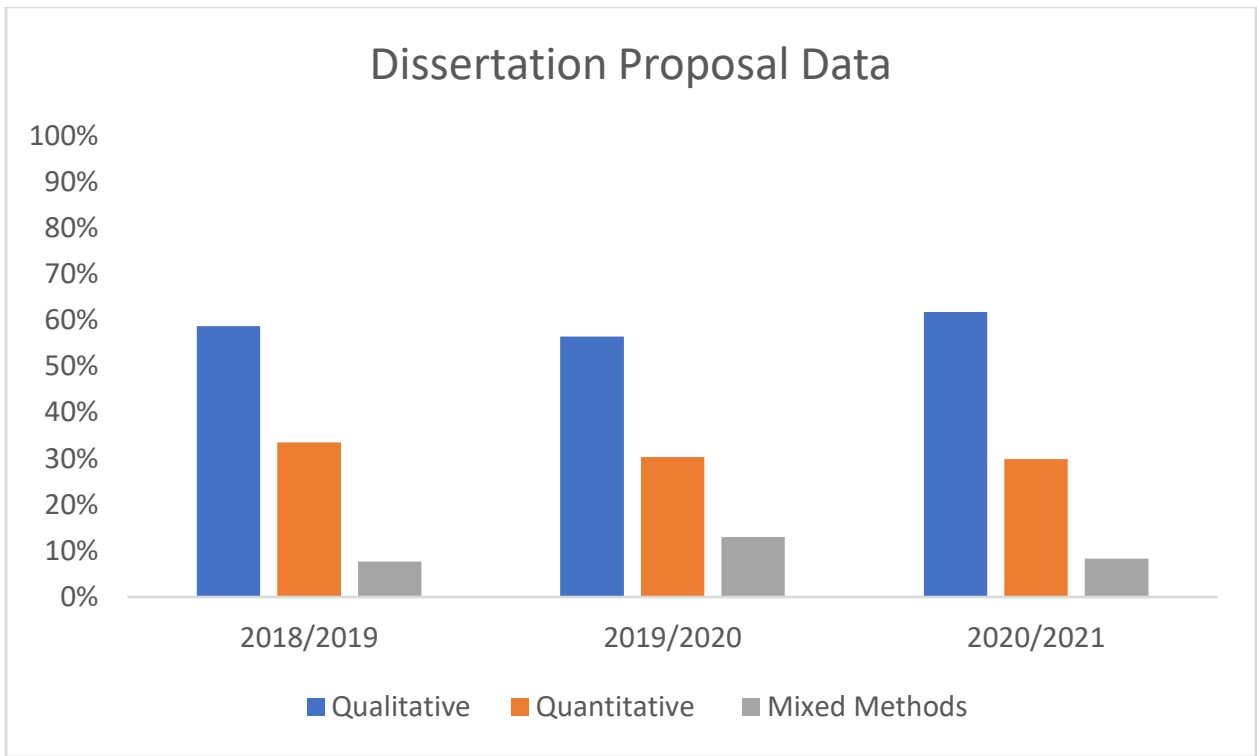

Figure 1. Dissertation Proposal Data

\section{Conference Registration Data}

Table 8 shows the percentage of students who indicated that they were undertaking a quantitative, qualitative, or mixed methods research project in the conference abstract that they submitted as part of their dissertation. It is not a requirement for students to discuss their chosen method in their conference presentations, however, many students opt to. Across the whole sample, an average of $16 \%$ of abstracts each year could not be coded according to whether the student was carrying out a quantitative, qualitative, or mixed methods dissertation. Given that the conference abstracts were anonymised by the programme administrators prior to being shared and subsequently coded, it was not possible to draw on other sources, such as the completed written dissertation theses to input this information.

Table 8

Dissertation Conference Abstract Data

\begin{tabular}{lccccc}
\hline \hline & $\mathbf{2 0 1 5 / 2 0 1 6 ( \% )}$ & $\mathbf{2 0 1 6 / 2 0 1 7 ( \% )}$ & $\mathbf{2 0 1 7 / 2 0 1 8 ( \% )}$ & $\mathbf{2 0 1 8 / 2 0 1 9 ( \% )}$ & $\mathbf{2 0 1 9 / 2 0 2 0 ( \% )}$ \\
\hline Qualitative & 74.4 & 70.2 & 68.2 & 62.2 & 66.9 \\
Quantitative & 16.5 & 21.0 & 24.0 & 31.7 & 25.3 \\
Mixed Methods & 9.1 & 8.9 & 7.8 & 5.9 & 7.8 \\
\hline Total & 121 & 124 & 129 & 167 & 130 \\
\hline \hline
\end{tabular}

The data presented show that the proportion of social science students utilising quantitative approaches in their final year dissertation projects has increased over time. In the academic year, 2015/2016, only $16.5 \%$ of students utilised quantitative methods in their dissertation. This increased to approximately one quarter of students by the academic year 2017/2018 and reached a peak at $31.7 \%$ in the academic year 2018/2019. Meanwhile, the proportion of students choosing to use 
qualitative approaches or to undertake a mixed methods project has slowly decreased over the academic years studied. For instance, in the academic year 2015/2016, almost three quarters of students used qualitative methods in their dissertation, this decreased to $67 \%$ at the most recent data collection point (2019/2020). See Figure 2.

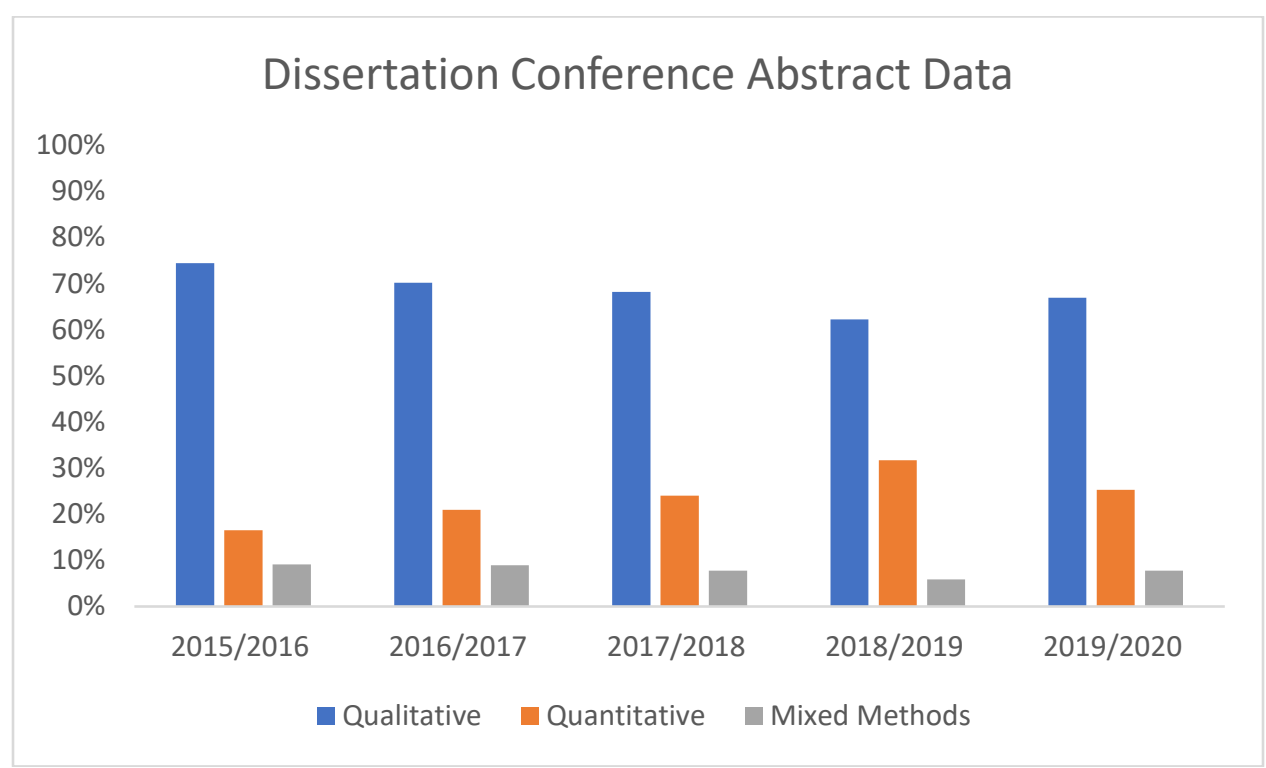

Figure 2. Dissertation Conference Abstract Data

\section{Discussion of the Data}

The module evaluation data indicates that students learnt a lot from the quantitative component of the compulsory second-year research methods module and that the majority planned on undertaking a dissertation project that used quantitative methods. Meanwhile, the dissertation proposal data shows that across each cohort, approximately one-third of students planned to use quantitative approaches in their final-year dissertation. In each year, over $55 \%$ of students planned to use qualitative approaches in their dissertations. Interestingly, whilst at the end of their quantitative methods training, over half of students surveyed indicated that they would like to use quantitative methods in their final-year dissertation, by the time students submitted their dissertation proposals, the percentage of students planning to use quantitative approaches was less than $40 \%$ (if we assume all those who stated mixed methods would use some quantitative methods).

The dissertation conference data show that, over the time period studied, the proportion of students undertaking a quantitative dissertation has increased. In $2018 / 2019$, almost $32 \%$ of students used quantitative methods in their dissertation 
compared to just $16 \%$ in the first year studied. This could suggest an increased acceptance of the role of number in the social sciences among the students in later cohorts. When comparing Figures 1 and 2, what is notable is the change in the proportion of students initially stating that they will utilise quantitative, qualitative, or mixed methods in their dissertations and the proportion of students who actually do. For instance, in the academic year 2019/2020, whereas upon registration 56.5\% of students intended to undertake a qualitative dissertation, this proportion increased to almost $70 \%$ by the time the dissertation conference took place.

What emerges from the data is that while students have an initial enthusiasm and interest in quantification and, indeed, often decide to study further optional quantitative methods modules (see Table 2), this does not always translate into them undertaking a quantitative dissertation. The decrease in the number of students choosing to utilise quantitative approaches in their final year dissertation is greatest between the time students complete their second-year quantitative methods training and when they initially register for the dissertation module (later in their second year of study). At this stage students have not been allocated supervisors and are not working with staff to develop their research projects or questions. Instead, this decision has been made independently suggesting that rather than individuals, the way in which the social sciences are framed both in the current curriculum and in the broader academic literature may play a key part in this decline. Indeed, students may not consider small scale quantitative projects as a viable option and be unfamiliar with the wealth of secondary quantitative data available to them, leading them to choose to undertake a qualitative project instead. It seems plausible that while students initially reviewed quantitative methods training positively, they are unable to translate this teaching and learning into a research project or research questions when creating a dissertation proposal.

\section{Reflecting on the Case of British Sociology}

This data may suggest that social science students in the UK have limited exposure to examples of how quantitative approaches can be used to explore sociological topics. The training that these students receive fuels their research interests and understanding of how to study the social world. Thus, a lack of exposure to quantification in the substantive parts of a student's training could render it difficult for them to design and develop sociological research questions and projects which utilise such techniques (Coxon 1973). This lack of exposure, in turn, could lead to a perpetuating cycle within UK social sciences where these skills deficits become entrenched and increasingly difficult to address, suggesting that the longer term success of the Q-Step project may depend on more profound curriculum change than simply exposing students to more and better taught quantitative methods. 
Indeed, Coxon (1973) earlier argued that the absence or scarcity of quantitative methods training in students' early academic career was problematic as it meant that students often developed fixed ideas of what sociology was and was not, prior to any exposure to or engagement with quantitative approaches. Often this leads to fixed orthodoxies which place quantitative approaches as oppositional to the aims of the discipline and, consequently, students may view quantitative methods training as "unnecessary, if not positively harmful" (Coxon 1973, 44). In light of this, Coxon $(1973,48)$ called for quantitative research methods training to become "an integral and early part" of sociology students' training. More recently, Scott (2005, paragraph 6.3) highlighted that, at the pre-university level, students are often taught a highly selective curriculum and argued that "many teachers have themselves been trained in the shrinking university syllabus, and they pass this constricted view of the subject on to their student." Thus, in consideration of the data presented above, it may be the case that students believe that learning about quantitative methods is important for their future employability, however, see them as somewhat tangential to their current studies and to research in their specific field at the present time.

An earlier national study by Williams et al. (2008) found that while less than half of the sociology students surveyed $(41.9 \%)$ agreed with the statement "On the whole I am not good at maths" and less than $20 \%$ agreed with the statement "One of the reasons I chose this degree is because I don't like maths," over $60 \%$ of respondents reported a preference for writing essays over analysing data. This may suggest that while sociology undergraduates are generally comfortable or even confident with number, they do not necessarily feel the same confidence about applying number to a sociological context.

It has been suggested that this resistance toward quantitative methods in British sociology may be a symptom of a broader issue of how the discipline is viewed and perceived. Previously, we have argued that distinct sociologies, "critique" and "analytic," have emerged as a result of a series of "cultural wars" in the development of the discipline (Williams et al. 2017). Compared to "critique" sociologies, "analytic" sociologies are those that aim "to produce descriptions and explanations of social phenomena" (Williams et al. 2017, 134). While these approaches to studying the social world cannot be seen in complete opposition or mutually exclusive, they do represent underlying tensions in the discipline surrounding the nature of social research. We have argued elsewhere that the extreme forms of these approaches, "have taken root in student perceptions of what sociology is." (Williams et al. 2017, 136) Thus, what emerges is a deep polemic divide within the discipline. One implication of this divide is that in addressing the quantitative deficit in British sociology, pedagogic strategies aimed at increasing students' confidence with quantitative techniques alone will not suffice. Instead, 
strategies are also needed to demonstrate the breadth, variety, and potential of sociological research.

\section{Conclusion}

This paper set out to explore whether the activities of the Cardiff University Q-Step Centre have led to an increase in the proportion of undergraduate students using quantitative approaches in their dissertations. While the authors maintain that it is important for students to utilise the most appropriate method in order to answer the research question posed, it seems reasonable to assume that the work and methodological preferences of students would reflect the contemporary priorities of the social science disciplines and students' own training.

The data presented in this paper suggests that social science students do feel they learn a lot during their second year quantitative methods training, and many see the utility of these approaches for their future employability. More than half of these students initially consider using the approaches learnt in their dissertation. There has been an increase in the percentage of students indicating that they would like to use quantitative approaches in their dissertation (if we assume that those stating mixed methods are using some quantitative methods). Dissertation conference data suggest that there has also been an increase in the proportion of students using quantitative methods in their final-year dissertations. While the number of students who eventually undertake a quantitative dissertation does decrease from when students write their initial proposals, this reduction is not as great as that between the end of the social research methods module and submitting proposals for the dissertation module.

It is suggested that the successes of the Q-Step initiative should be situated in an understanding that sociology and its analogous disciplines in the UK have and continue to demonstrate a preference for more critique approaches to studying the social world. The Q-Step project faces the challenge of not only demonstrating to students the utility of more analytic approaches to social sciences, but to the discipline as a whole, in order to truly encourage a stepwise change.

Following on from the findings presented in this paper, the authors continue to routinely collect survey data on the methodological decisions of students currently completing their dissertations (the 2020/21 cohort, for whom the module evaluation data and registration data is discussed in this paper). It is hoped that these data can augment the existing data to give a more complete picture of when and how students choose to collect and analyse data. Comparative research with other QStep institutions is also planned to see whether the same pattern can be observed in other universities. 


\section{References}

Allebon, L. 2013. "Impact Assessment for Centres of Excellence in Quantitative Methods." Bristol: Higher Education Funding for England.

Bechhofer, F. 1981. "Substantive Dogs and Methodological Tails: A Question of Fit." Sociology, 15(4): 495-505. https://doi.org/10.1177/003803858101500403

Bullock, K., R. Meadows, and I. Brunton-Smith. 2014. "'DiscoverQuants': Integrating Quantitative Methods (QM) and Substantive Teaching for First Year Undergraduate Sociology Students." Enhancing Learning in the Social Sciences, 6(2): 6-20. https://doi.org/10.11120/elss.2014.00033

Brookfield, C. 2016. "Teaching Quantitative Research Methods: The Employability Factor.” International Journal of Pedagogy, Innovation and New Technologies, 3(2): 10-19. https://doi.org/10.5604/01.3001.0009.5079

Brookfield, C. 2017. "'Quantification Is the Root of All Evil in Sociology' What Does It Add Up To? The Place of Quantitative Research Methods in British Sociology." PhD Diss; Cardiff University.

Carey, S. and K.S. Adenay. 2009. "The Development of Undergraduate Curricula in Quantitative Methods: Full Research Report ESRC End of Award Report" (RES-043-25-0004). Swindon: ESRC.

Coxon, A.M.P. 1973. "Formal Foundations for Research Methods: The Matching of Methodological Needs." International Journal of Mathematical Education in Science and Technology, 4(1): 43-49. https://doi.org/10.1080/0020739730040106

Cohn, E.G., and D.P. Farrington. 1990. "Differences between British and American Criminology: An Analysis of Citations." The British Journal of Criminology, 30(4): 467-482. https://doi.org/10.1093/oxfordjournals.bjc.a048051

Dale, A. J. and V. Higgins. 2008. "Increasing the Use of Large-Scale Social Surveys in Undergraduate Dissertations in the Social Sciences: A Pilot Project: Full Research Report, ESRC End of Award Report.” (RES-043-250002). Swindon: ESRC.

ESRC. 2005. "SSRC/ESRC the First Forty Years." UK: ESRC.

Falkingham, J., B. Harris, A. McGrew, and J. Powell. 2009. "Increasing the Use of Quantitative Methods in Social Science Undergraduate Dissertations: Full Research Report ESRC End of Award Report." (RES-043-25- 009). Swindon: ESRC.

Grundy, S., 2020. "The Past, Present and Future of Q-Step-A Programme Creating a Step-Change in Quantitative Social Science Skills." Numeracy, 13(1): Article 2. https://doi.org/10.5038/1936-4660.13.1.2 
HaPS. 2010. "International Benchmarking Review of UK Sociology". Durham:

The British Sociological Association. Available from:

https://esrc.ukri.org/files/research/research-and-impact-

evaluation/international-benchmarking-review-of-uk-sociology/ [Accessed:

$16^{\text {th }}$ April 2021].

Lynch, R., G. Maio, G. Moore, L. Moore, S. Orford, A. Robinson, C. Taylor, and

K. Whitfield. 2007. "ESRC/HEFCW Scoping Study into Quantitative

Methods Capacity Building in Wales. Final Report to the ESRC and

HEFCW." Cardiff University School of Social Sciences Working Paper

Series, vol. 91. Available from: http://orca.cf.ac.uk/78165/[Accessed: $22^{\text {nd }}$

April 2021].

MacInnes, J. 2009. "ESRC Initiative on Undergraduate Teaching of Quantitative

Methods. Interim Report of the Strategic Advisor." UK: ESRC.

MacInnes, J., H. Breeze, M. de Haro, M. Kandlik, and M. Karels. 2016.

"Measuring Up: International Case Studies on Teaching of Quantitative

Methods in the Social Sciences." London: British Academy.

MacInnes, J., J. Eichhorn, and P. Whybrow. Forthcoming. "Quantitative Methods in British Sociology: Evidence of a "Critical deficit'?" Sociology.

McCambridge, J., C. Waissbein, D. Forrester, and J. Strang. 2007. "What Is the Extent and Nature of Quantitative Research in British Social Work?"

International Social Work, 50(2): 265-271.

https://doi.org/10.1177/0020872807073992

Murtonen, M., and E. Lehtinen. 2003. "Difficulties Experienced by Education and Sociology Students in Quantitative Methods Courses." Studies in Higher Education, 28(2): 171-185. https://doi.org/10.1080/0307507032000058064

NCRM. No date. "Advancing Social Science Research Methods" [Brochure].

Nuffield Foundation. 2014. "Aims and Activities of the Q-Step Centres."

Available from:

https://www.nuffieldfoundation.org/sites/default/files/files/Aims\%20and\%20 Activities\%20of\%20the\%20Q-Step\%20Centres(1).pdf [Accessed: 22nd April 2020].

Parker, J., A. Dobson, S. Scott, M. Wyman, and A. Sjöstedt Landén. 2008. "International Benchmarking Review of Best Practice in the Provision of Undergraduate Teaching in Quantitative Methods in the Social Sciences." Swindon: ESRC.

Payne, G., M. Williams, and S. Chamberlain. 2004. "Methodological Pluralism in British Sociology." Sociology, 38(1): 153-163. https://doi.org/10.1177/0038038504039372

Rice, R., P. Burnhill, M. Wright, and S. Townsend. 2001. "An Enquiry into the Use of Numeric Data in Learning and Teaching: Report and Recommendations for UK Higher Education." University of Edinburgh. 
Available from:

https://www.era.lib.ed.ac.uk/bitstream/handle/1842/2504/DataReport.PDF?se quence $=1 \% 20$ [Accessed: 1st July 2017].

Roberts, A. 2012. Quantitative Skills: Learning Lessons from Overseas, paper presented to British Academy, London, 23rd April 2012.

Scott, J. 2005. "Sociology and Its Others: Reflections on Disciplinary Specialisation and Fragmentation.” Sociological Research Online, 10(1). https://doi.org/10.5153/sro.1055

Williams, M., G. Payne, L. Hodgkinson, and D. Poade. 2008. "Does British Sociology Count? Sociology Students' Attitudes Toward Quantitative Methods." Sociology, 42(5): 1003-1021. https://doi.org/10.1177/0038038508094576

Williams, M., Sloan, L., Cheung, S.Y., Sutton, C. Stevens, S., Runham, L. 2015. "Can't Count or Won't count? Embedding Quantitative Methods in Substantive Sociology Curricula: A Quasi Experiment.” Sociology, 50(3): 435-452. https://doi.org/10.1177/0038038515587652

Williams, M., L. Sloan, and C. Brookfield. 2017. "A Tale of Two Sociologies: Analytic Versus Critique in UK Sociology." Sociological Review Online, 22(4). https://doi.org/10.1177/1360780417734146 